\title{
Bermejo-Luque, Lilian. Giving Reasons. A Linguistic-Pragmatic Approach to Argumentation Theory
}

\section{Springer, Argumentation Library, Dordrecht, 2011,} volume 20,209 pp

\section{Andone}

Published online: 25 November 2011

(C) The Author(s) 2011. This article is published with open access at Springerlink.com

Bermejo-Luque's book Giving Reasons has the ambition of developing a new theoretical approach to argumentation that integrates logical, dialectical and rhetorical aspects. The author uses speech act theory to realize her ideal of 'a linguistic-pragmatic approach' to argumentation. After a severe criticism of the major existing approaches to the study of argumentation, the author develops what she claims to be "a systematic and comprehensive theory of the interpretation, analysis and evaluation of arguments."

\section{Outline}

Chapter 1, Argumentation and Its Study, aims at offering a critical survey of classical backgrounds and modern studies in the field of argumentation theory. After a swift introduction to the classical background in logic, dialectic and rhetoric, Bermejo-Luque takes us directly to the recent developments in argumentation studies. An enumeration of these new developments seems to suffice to draw the conclusion that each current model has established itself within one of the classical approaches. For instance, informal logic is a theory within the logical approach, the new Rhetoric finds its place within the rhetorical approach, and the pragmadialectical theory within the dialectical approach.

Why Do We Need a New Theory of Argumentation? comes as a natural question in the title of Chapter 2. Bermejo-Luque's answer is as simple as radical. She argues that all current theories have drawbacks and weaknesses making them unsuitable for the analysis and evaluation of argumentation. Thus, some theories embrace a deductivist ideal of justification which leaves aside the pragmatic conditions for

C. Andone $(\square)$

Department of Speech Communication, Argumentation Theory and Rhetoric,

University of Amsterdam, Spuistraat 134, 1012 VB Amsterdam, The Netherlands

e-mail: C.Andone@uva.nl 
argumentation as an activity of giving reasons. Pragmatic proposals, in turn, are dubbed instrumentalist, because they offer "criteria for deciding on the value of acts of arguing as means for achieving certain goals, such as persuading a universal audience or resolving a difference of opinion" (p. 23). Therefore, the author is of the opinion that a new normative model of argumentation is needed that overcomes the problems of the current approaches. The model should, according to BermejoLuque, be "characterizing what justification is, [...] by thinking of justification as the value that constitutes argumentation as an activity" (p. 18). It remains to be seen in the following chapters what the author exactly means with this remark.

In Chapter 3, Acts of Arguing, the author first criticizes once more the pragmatic approaches to argumentation by focusing this time on the pragma-dialectical theory. Although this theory provides a normative framework for the analysis and evaluation of argumentation by understanding argumentation as a speech act complex, it is seen as defective in three respects: (a) it advocates that the perlocutionary goal of argumentation is to convince, (b) it contends that "the claim for which the speaker argues is not part of the act of arguing, but is another illocutionary act linked to the sentences uttered in argumentation" (p. 59), and (c) it regards argumentation as complex because "arguing can consist of more than one sentence" (p. 59). To overcome these apparent problems, Bermejo-Luque proposes a model in which argumentation is a second-order speech act complex composed of the speech act of adducing and the speech act of concluding. These speech acts are characterized as second order "because they can only be performed by means of a first order speech act—namely, constative speech acts" (p. 60). The author's model consists in formulating conditions for putting forward a reason as an illocutionary act (also referred to as adducing), for putting forward a target-claim as an illocutionary act (also referred to as concluding), and for the complex illocutionary act of arguing.

Chapter 4 concerns The Logical Dimension of Argumentation. Bermejo-Luque emphasizes that previous criticisms of formal logic as a tool for evaluating natural language argumentation are correct. She argues that Toulmin's conception of logic as a non-formal normative theory of inference is instead fruitful, but normatively it is insufficient. Therefore, the author proposes that the data, the warrant, the rebuttal, and the backing in Toulmin's model be 'completed' by adding an ontological qualifier, which is "an explicit reference to the type of force with which we put forward a given propositional content in claiming" (p. 115). Moreover, BermejoLuque suggests that the conclusion be 'completed' with an epistemic qualifier, which is "an explicit reference to the type of force with which we put forward a claim in concluding it" (p. 115).

Chapter 5 moves to The Dialectical Dimension of Argumentation. BermejoLuque tries to give an account of the dialectical normative conditions of argumentation by establishing whether argumentation fulfills certain dialectical criteria. She argues that putting forward a reason for a claim involves dialectical conditions that are "constitutively normative for argumentation as a justificatory device and regulatively normative for argumentative as a persuasive device" (p. 121). What is one to make of this idea remains unclear. 
As one might expect, in Chapter 6 The Rhetorical Dimension of Argumentation is investigated. After disagreeing with the way in which informal logic, pragmadialectics and Tindale's rhetorical model have integrated rhetorical aspects into argumentation theory, Bermejo-Luque emphasizes that her normative model integrates a rhetorical perspective in order to determine "how well a piece of argumentation does at accomplishing justification" (p. 140). At the end of this chapter, the author turns to non-verbal argumentation, which she finds important because it has "rhetorical power to induce beliefs" (p. 163).

The final chapter, Chapter 7, deals with Argument Appraisal, which includes a semantic appraisal of argumentation and a pragmatic appraisal of argumentation. With regard to the semantic appraisal — a term which remains undefined-BermejoLuque deals with enthymeme and incomplete argumentation. With regard to the pragmatic appraisal of argumentation-again undefined-she tries to show that there is a kind of argumentative flaw which consists in a failure to meet the pragmatic conditions for arguing. One such example is, according to BermejoLuque, the fallacy of the ad baculum which gives the appearance of argumentation to a threat.

\section{Comments}

Giving Reasons aspires to provide a coherent, systematic and comprehensive model for argument analysis and evaluation which overcomes the shortcomings of the current models and approaches to argumentation. This model, in the author's view, should be both descriptive and normative. It should be used to analyze argumentation as it occurs in practice and it should provide a standard for evaluating the reasonableness of argumentative moves.

The book raises a number of interesting issues, but it leaves much room for doubt. In what follows, I will express my reservations with regard to several issues discussed in the book, although many more aspects remain open for substantial criticism (for a criticism of several other aspects in the book, see Biro and Siegel 2011; Freeman 2011; Hitchcock 2011; Pinto 2011).

One of my reservations concerns the general approach undertaken to develop a new argumentative model. Bermejo-Luque's approach consists in a hasty criticism of all the theories which have so far made an attempt at developing such a model. Basically, the author is of the opinion that every theory lacks some or more fundamental features which should make it fully applicable to the analysis and evaluation of argumentative discourse. In a nutshell, to use the author's own words, these theories "provide neither a coherent account of how good (as opposed to bad) argumentation achieves its perlocutionary effect, nor suitable criteria to whether the argumentation itself is good" (p. 33). Whether this is indeed the case would be very difficult to know. The author is so much in a hurry to provide criticism that most of the time the result is too summary to enable the reader to get a clear picture of what she means by her criticism. At other times, when the criticism is more elaborate, the theories discussed are not done full justice to. 
A case in point is the critical treatment of the pragma-dialectical approach. After mentioning briefly that the founders of this theory, van Eemeren and Grootendorst, envisage argumentation as aimed at resolving a difference of opinion, BermejoLuque moves on to three problems. The first problem is that convincing is regarded as the only perlocutionary goal of arguing. Bermejo-Luque contends that "convincing is just one of the goals that we may pursue by arguing and, more importantly, that there are means to achieve this goal other than argumentation: for example, we can also convince our addressee by bribing or threatening them, or more generally, just by making assertions in certain conditions" (p. 59). While it remains a secret what it means making 'making in certain conditions,' anyone reading carefully about the pragma-dialectical approach will know that van Eemeren and Grootendorst (1984: 26-28) refer only to those perlocutionary effects which are intentional, based on understanding and realized on rational grounds. It is starting from these criteria that pragma-dialectics takes convincing as the perlocutionary effect of arguing. It might perhaps be the case that convincing can also be achieved by the means Bermejo-Luque mentions, but the relevant question here is whether argumentation is an attempt at achieving other goals than convincing.

The second problem raised by Bermejo-Luque is that pragma-dialectics equates, in her interpretation, arguing with the illocutionary act of adducing, but "concluding [...] together with the speech act of adducing would constitute the complex speech act of arguing" (p. 59). Once again, a careful reading of pragma-dialectics is enough to realize that this criticism is based on a misunderstanding. According to van Eemeren and Grootendorst (1984: 33), "advancing a constellation of statements can only be regarded as a performance of the speech act argumentation if the sentences uttered stand in a particular relationship to another sentence (or collection of sentences) whose utterance counts as the advancing of an expressed opinion." Van Eemeren and Grootendorst argue that in the complex illocutionary act of argumentation at least two assertions are combined and argumentation is defined in terms of the relationship of this combination on a higher textual level to a third assertion, the standpoint.

The quote just given (van Eemeren and Grootendorst 1984: 33) solves also the third pragma-dialectical problem pointed out by Bermejo-Luque according to which argumentation is viewed as a complex speech act because arguing consists of more than one sentence. The complexity should come instead, according to the author, because the act of concluding is part of arguing. This view, however, as just shown, is based on an incomplete reading.

Apart from the way in which the various theories are approached critically, I have some reservations with regard to the model developed in the book. To begin with, it is very difficult, if not impossible, to see exactly what the model the author is referring to involves. Bermejo-Luque does not go further than formulating speech act conditions for various kinds of illocutionary acts, such as arguing, putting forward a reason, putting forward a target-claim (Chapter 3). Later, the author speaks again of "a model of argumentation" (Chapter 4), referring in this case to nothing more than Toulmin's model to which an ontological and an epistemic qualifier are added. 
Why and in what sense do speech act conditions constitute a model? In addition, one would like to know the purpose for which speech act conditions are formulated. Yet an even more serious problem is that the formulation of the speech act conditions is done in an ad hoc fashion, without any concern whatsoever for the precision, systematicity and coherence the author claims the model to have. To name just one example, Bermejo-Luque formulates the following conditions for "reason as an illocutionary act", in which $S$ is the speaker, $L$ is the listener, $C$ is the act of concluding, $R$ is the reason and $R$ ' is the first order claim (p. 70):

Preparatory conditions:

(i) $S$ believes that a claim $R$, having such and such pragmatic force, may be taken to be correct by $L$

(ii) It makes sense to attribute to $S$ a conditional claim, with a certain pragmatic force, whose antecedent is ' $R$ is correct,' and whose consequent is ' $C$ is correct'

Although at this stage the reader neither knows the propositional content of a reason, nor the intended perlocutionary effect of a reason, one is presented with the formulation of some preparatory conditions. These conditions, if correctly formulated, should make clear what the required point of departure is when a reason is put forward. Instead, the reason $R$ and a claim are equated with each other and allocated a mysterious ('such and such') 'pragmatic' force.

Propositional content condition:

(iii) The content of the reason is that a claim R' is correct.

Strangely, the content of a reason is that a first order claim that lies at the basis of the act of adducing is correct. Is that indeed so in all cases? Should one not take into account that an arguer can bring reasons for one's claim or against someone else's claim?

Sincerity conditions:

(iv) $S$ believes the propositional content of $R$ in a certain way and to a certain extent, namely, the way and extent that correspond to the pragmatic force of the claim $R$

(v) $S$ believes that $R$ being correct is a means to show that a target-claim $C$ is correct

What is one to make of this circular formulation: $S$ believes the propositional content of $R$ in a certain way and to a certain extent, namely, the way and extent that correspond to the pragmatic force of the claim $R$ ? As sincerity conditions, should these conditions not specify the speaker's wishes and intentions?

Essential condition:

(vi) Adducing $R$ with such and such pragmatic force is a means to show that a target-claim $C$ is correct

What the speaker aims to achieve with his utterance is an essential question which remains unanswered in this formulation. The essential condition should show what distinguishes the utterance of bringing forward a reason from other utterances. 
Combining a characterization of the point of the illocutionary act with indicating the associated perlocutionary aim could make clear this distinction.

In their current formulation, the speech act conditions do not enable the identification of an utterance as a reason and do not give any indication of the conditions under which a reason is correct. Besides, speech act conditions should have different consequences for the speaker and the addressee, but this desideratum cannot be fulfilled because the addressee is not taken into account.

The task of analyzing and evaluating argumentative discourse, which the author embraces, means that besides a descriptive dimension, the model should have a critical dimension. Unfortunately, the model proposed in the book falls short of this ideal. There is no illustration with examples from argumentative practice that makes clear what the explanatory potential of the model is and what its applicability is in reality. Furthermore, the incorporation of the logical, dialectical and rhetorical dimensions of argumentation, which the author strongly advocates in her book, is still to come.

Not only the content, but also the style of the book leaves much room for improvement. The book is written in a very abstract and complicated style, often goes from one idea to the other without a clear transition. In addition, it contains numerous repetitions and spelling mistakes. The final chapter does not advance a conclusion and ignores presenting the results obtained in the book.

Despite these objections, I believe that Giving Reasons will be of interest to argumentation theorists, as it raises some important issues.

Open Access This article is distributed under the terms of the Creative Commons Attribution Noncommercial License which permits any noncommercial use, distribution, and reproduction in any medium, provided the original author(s) and source are credited.

\section{References}

Biro, J., and H. Siegel. 2011. Argumentation, arguing, and arguments: Comments on Giving Reasons. Theoria 72: 279-287.

Eemeren, F.H. van., and R. Grootendorst. 1984. Speech acts in argumentative discussions. A theoretical model for the analysis of discussions directed towards solving conflicts of opinion. Dordrecht: Foris Publications.

Freeman, J.B. 2011. The logical dimension of argumentation and its semantic appraisal in BermejoLuque's Giving Reasons. Theoria 72: 289-299.

Hitchcock, D. 2011. Arguing as trying to show that a target-claim is correct. Theoria 72: 301-309.

Pinto, R.C. 2011. The account of warrants in Bermejo-Luque's Giving Reasons. Theoria 72: 311-320. 